Karen M. Lauridsen*

\title{
Text \& Translation - Introduction to the thematic section
}

A couple of years ago, the Conférence Internationale d'Instituts Universitaires de Traducteurs et Interprètes (CIUTI) decided to make the research initiatives of the member institutions more visible by having a research seminar or colloquium back-to-back with the annual general assembly. In 2000 the Aarhus School of Business hosted the meeting as well as a one-day Text \& Translation seminar.

The papers in the following thematic section were originally presented at the seminar and may be considered a snap shot of some of the research discussions and activities taking place at present within the CIUTI schools and the T\&I community at large.

Roughly speaking, the papers fall in two sections: the first one is concerned with the quality assessment of student or professional performance, the other with research methodology ${ }^{1}$.

On the basis of the results of his Ph.D. thesis, Waddington discusses two methods to evaluate student translations, one based on error analy-

1 A sixth paper was presented by Inger Askehave \& Karen Korning Zethsen, reporting on a recently completed project analysing patient package inserts. This project has been documented in Askehave \& Zethsen (2000a) "Inter-generic and inter-linguistic Translation of Patient Package Inserts" in proceedings of the 12th European Symposium on Language for Special Purposes: Language for special purposes: perspectives for the New Millennium. Gunter Narr Verlag, Tübingen. (2000b) "Medical Texts Made Simple - Dream or Reality?" in Hermes 25. 63-74. (2000c) The Patient Package Insert of the Future, report for the Danish Ministry of Health. The Aarhus School of Business.

* Karen M. Lauridsen

Faculty of Modern Languages

The Aarhus School of Business

Fuglesangs Allé 4

DK-8210 Aarhus $V$ 
sis and one based on a holistic approach. Whereas most other writing on translation quality assessment has been theoretical and descriptive, Waddington has embarked on an empirical study for his thesis. He defines the methods of assessment and carries out research into the reliability and validity of the methods typically employed by university teachers, viz the error analysis and holistic approach, respectively. The conclusion of his study is that the most reliable quality assessment method is a combination of the two approaches.

Lamberger-Felber also discusses methods of quality assessment. Based on her Ph.D. thesis, she demonstrates considerable differences between objective descriptions using quantifiable parameters and subjective evaluations of the same speeches by twelve professional conference interpreters, the conclusion being that any objective text profile will appear unsatisfactory when checked against the subjective evaluation of source texts by the interpreters themselves.

Lamberger-Felber further applies different methods to test hypotheses regarding the influence of the interpreter using a speaker's manuscript on interpreter performance. She demonstrates strengths and weaknesses of the different methodological tools used and makes concrete proposals for further research.

Mason, Gerzymisch-Arbogast, and Gile also discuss methodological issues. Based on the study of the phenomenon of junction, Mason discusses the status of translator behaviour as evidence of norms of language behaviour; by using examples from French-English translations, he demonstrates that taking translator behaviour to reflect norms of language behaviour is indeed problematic.

Mason also discusses the status of contrastive linguistics. Based on his own research findings, he warns that the use of quantitative studies within translation studies, including those based on analysis of machinereadable corpora, should also be taken with a grain of salt as there is a whole set of important qualitative parameters which will then be disregarded unless quantitative and qualitative parameters are combined.

Gerzymisch-Arbogast illustrates some methodological principles for translation research and for writing theory-related research papers, a piece of advice for doctoral students and other young scholars. Taking as her starting point the fact that papers in Translation studies take many different forms, not always complying with the given norms, she offers 
some examples of good practice, demonstrating the basic structural dimensions of writing a research paper. Particular emphasis is given to the problem of writing a state-of-the-art section, an exercise that often proves difficult for young scholars.

Given that 'translation research can present no clearly useful application to society (...), and in that respect it remains within basic rather that applied research,' Gile discusses potentially useful projects for students in the T\&I training environment and suggests useful kinds of applied Translation research projects. He states that 'students should be encouraged to go as far as reasonable in their personal contribution' and that 'supervisors should try to maximise project quality and scale by proper management.' Thus, his paper not only lists possible projects; in it, Gile also discusses the important role of the supervisor towards the supervisee.

The papers thus focus on two issues that should be at the top of the agenda at any CIUTI school: How to assess quality in translation and interpreting? And how to design methodologically sound research projects and thus also improve the quality of translation and interpretation research. 
